\title{
Overexpression of zeaxanthin epoxidase gene from Medicago sativa enhances the tolerance to low light in transgenic tobacco
}

\author{
Yuman $\mathrm{CaO}^{1 *}$, Zhiqiang Zhang ${ }^{2 *}$, Tong Zhang ${ }^{1}$, Zhang You ${ }^{1}$, Jincai Geng ${ }^{3}$, \\ Yafang Wang ${ }^{1}$,Tianming $\mathrm{Hu}^{1 \otimes}$ and Peizhi Yang ${ }^{1 凶}$ \\ 1Department of Grassland Science, College of Animal Science and Technology, Northwest A\&F University, Yangling, Shaanxi, 712100, China; \\ ${ }^{2}$ College of Grassland Resources and Environment, Inner Mongolia Agricultural University, Huhhot, Inner Mongolia, 010000, China; ${ }^{3}$ Grassland \\ Management Station of Shaanxi Province, Xi'an, Shaanxi, 710016, China
}

Zeaxanthin epoxidase (ZEP) plays an important role in xanthophyll cycle which is a process closely related to photosynthesis. However, an impact of ZEP on low-light stress has not been studied. In this study, the functions of an alfalfa (Medicago sativa) zeaxanthin epoxidase gene, MsZEP, in response to low-light stress were investigated by heterologous expression in tobacco (Nicotiana tabacum). Under normal light conditions, the measured parameters were not significantly different between transgenic and wild-type (WT) plants except for non-photochemical quenching value and chlorophyll a content. However, the differences were detected under low-light stress. We found that MsZEP-overexpression tobacco grew faster than WT $(p \leq 0.05)$. The leaf fresh weight and leaf area of transgenic plants were significantly higher, and the number of stomata was greater in MsZEP-overexpression tobacco. As for photosynthetic characteristics, quantum yield of PSII (DPSII) and maximal photochemical efficiency of PSII $\left(F_{\mathrm{v}} / F_{\mathrm{m}}\right)$ were not significantly different, whereas non-photochemical quenching (NPQ), net photosynthetic rate (Pn), stomatal conductance (Gs) and transpiration rate (Tr) of $M s Z E P$-overexpression tobacco were significantly higher than in WT plants. However, no significant difference was detected between the two types of tobacco in chlorophyll and carotenoids content. In conclusion, MsZEP can improve the ability of tobacco to withstand low-light stress, which might be due to its stronger photosynthetic activity and the improvement of stomatal density under low light.

Key words: Medicago sativa, low-light tolerance, zeaxanthin epoxidase, overexpression

Received: 10 January, 2018; revised: 21 May, 2018; accepted: 15 July, 2018; available on-line: 08 September, 2018

更-mail: hutianming@126.com (TH) yangpeizhi@126.com (PY)

*Equally contributed to this paper

Abbreviations: $\mathrm{Ax}$, antheraxanthin; $\mathrm{Chl}$, chlorophyll; $F_{\mathrm{v}} / F_{\mathrm{m}}$, maximal photochemical efficiency of PSII; Gs, stomatal conductance; MsZEP, Medicago sativa zeaxanthin epoxidase gene; NPQ, non-photochemical quenching; $\mathrm{Pn}$, net photosynthetic rate; WT, wild-type plants; DPSII, quantum yield of PSII; ZEP, Zeaxanthin epoxidase; Zx, zeaxanthin; $\mathrm{Vx}$, violaxanthin

\section{INTRODUCTION}

Light is the most important environmental factor which can influence the growth and development of plants (Zoratti et al., 2014). The photosynthetic apparatus absorbs radiant energy and converts it to stable chemical energy which plants can use to grow and develop. Light intensity and quality directly affect photo- synthesis of plants (Romanowska et al., 2008; Lee et al., 2007; Farquhar et al., 2001; Sæbø et al., 1995). Plants have evolved some mechanisms to adapt to different irradiance levels, which makes them capture and use the limited light efficiently while avoiding the potentially damaging effects of excessive irradiance (Kang \& Zhu, 2003). The plants response to irradiance change includes changes in the number of chloroplasts per unit leaf area, altered leaf thickness and photosynthetic capacity per unit leaf area, leaf movement, altered xanthophyll cycle, chlorophyll (Chl) concentration and others (Pastenes et al., 2005; Latowski et al., 2004; Murchie \& Horton, 1997).

In both higher plants and green algae, the xanthophyll cycle is involved in thermal energy dissipation, the main way of removal of the excess light energy (Hieber et al., 2000; Bugos et al., 1998; Demmig-Adams \& Adams, 1996; Yamamoto \& Higashi, 1978). In this cycle, there are three pigments to interconvert, including zeaxanthin $(\mathrm{Zx})$, antheraxanthin $(\mathrm{Ax})$ and violaxanthin $(\mathrm{Vx})$ and two enzymes, zeaxanthin epoxidase (ZEP) and violaxanthin de-epoxidase which catalyze the cycle. Plants can dissipate excess light energy through these three components conversion. Zeaxanthin epoxidase (ZEP) is an important enzyme which catalyzes the conversion of $\mathrm{Zx}$ to $\mathrm{Ax}$ and $\mathrm{Vx}$. This reaction is performed mainly under low light, while it weakens and even vanishes under strong light (Schwarz et al., 2014; Wang et al., 2008; Frommolt et al., 2001). The conversion is closely related not only to xanthophyll cycle but also to ABA biosynthesis and carotenoid biosynthesis (DellaPenna \& Pogson, 2006; Nambara \& Marion-Poll, 2005). ZEP gene was studied in various plants including Arabidopsis (Barrero et al., 2005; Xiong et al., 2002), Nicotiana plumbaginifolia (Audran et al., 1998; Marin et al., 1996), tomato (Wang et al., 2008) and rice (Agrawal et al., 2001), but these studies mainly focused on the role of ZEP in ABA biosynthesis, during osmotic or strong-light stress and during seeds development. However, little is known about its response under low light.

Alfalfa is a major legume forage in the world because of its high nutritional value, high yield and wild adaptability. We previously isolated a ZEP gene from alfalfa and studied its role in transgenic tobacco under drought and salt stress (Zhang et al., 2016). Xanthophyll cycle is closely related to photosynthesis and photoinhibition under low light and ZEP is involved in this cycle. Therefore, we further studied the physiological function of this gene in response to low-light stress using MsZEP-overexpression Nicotiana tabacum plants. 


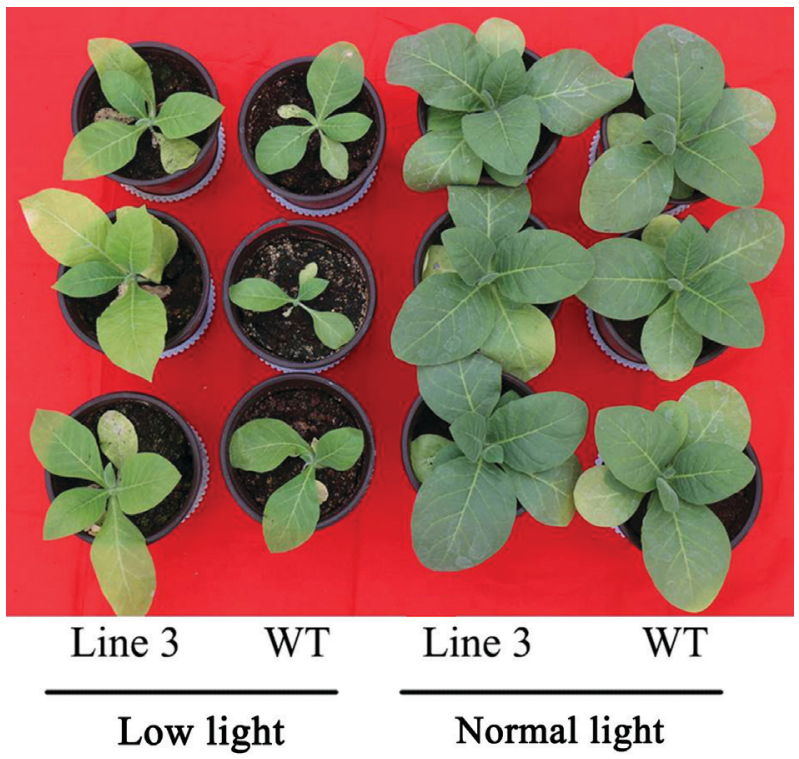

Figure 1. Effect of weak-light stress on the growth of WT and transgenic plants.

\section{MATERIALS AND METHODS}

Plant material and treatments. Wild-type (WT) tobacco (Nicotiana tabacum) and the MsZEP-overexpression line (Line 3) were previously described (Zhang et al., 2016). Seeds of these two lines were surface-sterilized with $75 \%$ ethanol for $30 \mathrm{~s}$, and $0.5 \%$ sodium hypochlorite solution for $10 \mathrm{~min}$ and then rinsed with sterile distilled water 4-5 times. Seeds of MsZEP-overexpression tobacco were germinated and grew on Murashige and Skoog medium (Murashige \& Skoog, 1962) with 0.35\% plant phytagel and $30 \mathrm{mg} / \mathrm{L}$ hygromycin $\mathrm{B}$ at $24^{\circ} \mathrm{C}$ under 16-h photoperiod for two weeks, and seeds of WT grew in the same conditions but without hygromycin B. These 14-day-old seedlings were transplanted to plastic pots filled with sandy soil and divided into two groups at random. One group was grown at $25^{\circ} \mathrm{C}$ and $40 \mu \mathrm{mol}$ $\mathrm{m}^{-2} \mathrm{~s}^{-1}$ for 3 weeks before the transfer to $25^{\circ} \mathrm{C}$ and 200 $\mu \mathrm{mol} \mathrm{m} \mathrm{m}^{-2} \mathrm{~s}^{-1}$. The other group was grown at $200 \mu \mathrm{mol}$ $\mathrm{m}^{-2} \mathrm{~s}^{-1}$. After growing in soil for 6 weeks, plants were harvested and immediately frozen in liquid nitrogen and stored at $-80^{\circ} \mathrm{C}$ until use.

Growth measurements. The leaves of WT and $M s Z E P$-overexpression tobacco were harvested after two different treatments. Leaf fresh weight and area for each tobacco plant group were measured with electronic scales and a leaf-area meter, respectively. The density of stomata was calculated using a optical microscope.

Photosynthetic capability measurement. Chlorophyll fluorescence was measured using a pulse-amplitude-modulation chlorophyll fluorometer (Heinz-WalzGmbH, Effeltrich, Germany). ФPSII, Fv/Fm ratio and NP were recorded during a saturating photon pulse (4000 $\mu \mathrm{mol} \mathrm{m} \mathrm{m}^{-2} \mathrm{~s}^{-1}$ ) using a whole plant (Yang et al., 2014). Gs, Tr and Pn of transgenic and WT plants were determined using a Li-COR 6400 system (Lincoln, NE, US) (Elhaddad et al., 2014). Measurements were taken from three leaves harvested from three separate plants of each line.

Pigments measurements. Leaf pigments concentrations (Chl a, Chl b, carotenoids) were determined spectrophotometrically according to Arnon (1949) by homogenizing tissue in $80 \%$ acetone. Extract absorbance
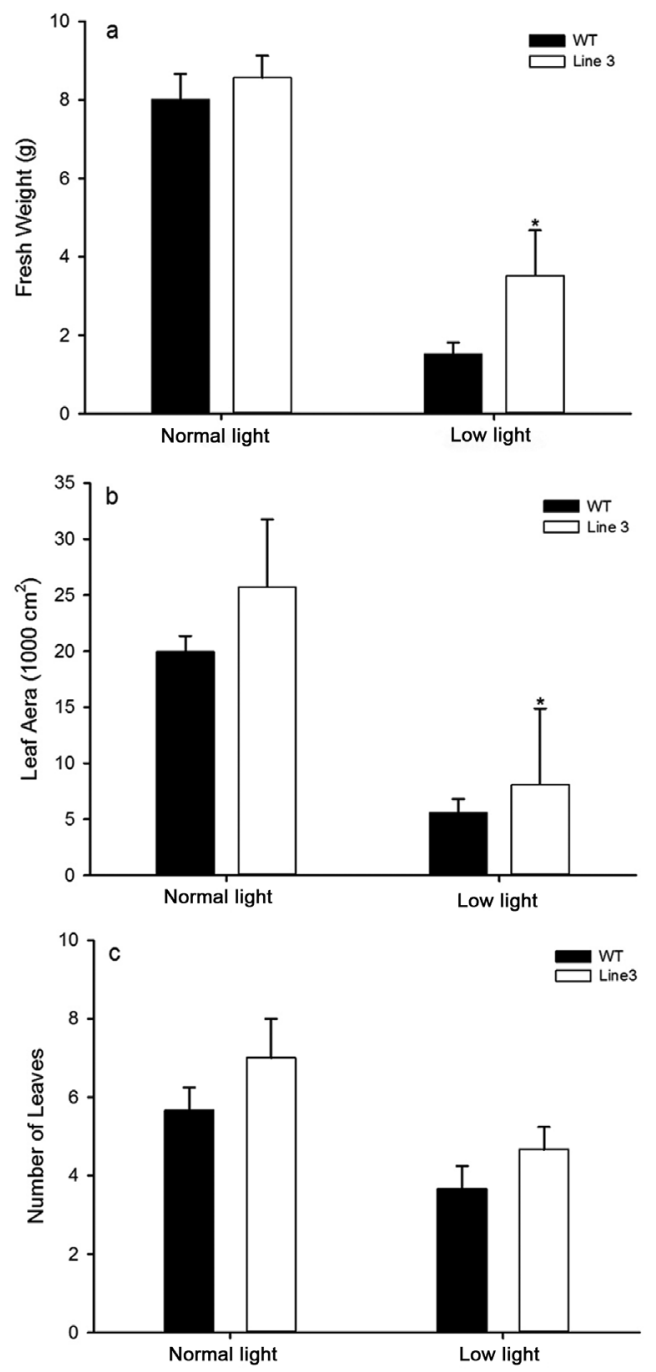

Figure 2. Effect of weak-light stress on leaf characteristics of WT and transgenic plants.

(a) Fresh matter of total leaves. (b) Total leaf size. (c) Leaves number. Bars represent the means \pm S.E. $(n=3)$; asterisk indicates $p \leq 0.05$.

was measured at the wavelength of 645,663 and $470 \mathrm{~nm}$ with 5100UV spectrophotometer (Shanghai, China).

Statistical analysis. All data are presented as the means \pm standard errors (S.E.) from three biological replicates of each experiment. Statistical significance was calculated using Student's $t$-test. The significant differences among various treatment groups are represented

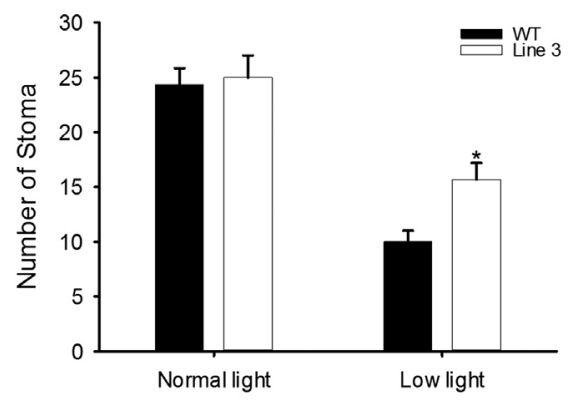

Figure 3. Effect of weak-light stress on the density of stomata of WT and transgenic plants.

Bars represent the means \pm S.E. $(n=3)$; asterisk indicates $p \leq 0.05$. 
by '*' for $p \leq 0.05$ and '**' for $p \leq 0.01$. Analyses were performed with IBM SPSS Statistics 18.0 software. Figures were created using SigmaPlot 10.0 (Systat Software, Inc., Germany).

\section{RESULTS AND DISCUSSION}

\section{Plant growth and development under low-light conditions}

Light intensity plays an important role in plants growth and development (Pan \& Guo, 2016). Under the maximum light intensity required by plants, the plant productivity decreased by $1 \%$ when the light intensity dropped by $1 \%$ (Wilson et al., 1992). We observed that low light decreased the growth rate of tobacco, whereas overexpressing MsZEP enhanced the ability of tobacco to withstand the low-light stress (Fig. 1).

To further understand the effect of weak-light stress on the growth of both tobacco types, we determined the leaf fresh weight, the number of leaves, and leaf area. We found that the leaf fresh weight (Fig. 2a) and leaf area
(Fig. 2b) of both MsZEP-overexpression and WT tobacco decreased dramatically after weak-light treatment, but the leaf weight and leaf area of MsZEP-overexpression tobacco were significantly higher than in WT lines. The number of leaves of transgenic plants was higher than in wild-type (Fig. 2c). Some research reported that leaves in low light are larger than leaves in high light (Lichtenthaler et al., 1981; Bjorkman et al., 1972).

\section{The number of stomata}

Lichtenthaler and coworkers (Lichtenthaler et al., 1981) reported that light intensity could change stomatal density. To understand the effect of MsZEP gene on the numbers of leaf cells and stomata, the lower epidermis of leaf was observed using an optical microscope. MsZEP-overexpression tobacco showed higher stomatal density under low light conditions, while the stomatal density was comparable between wild-type and $M s Z E P$-overexpression plants under normal growth conditions (Fig. 3). ZEP catalyzes the conversion of Zx into $\mathrm{Vx}$, which is an essential part of ABA biosynthesis (Nambara \& Marion-Poll, 2005). As reported previous-
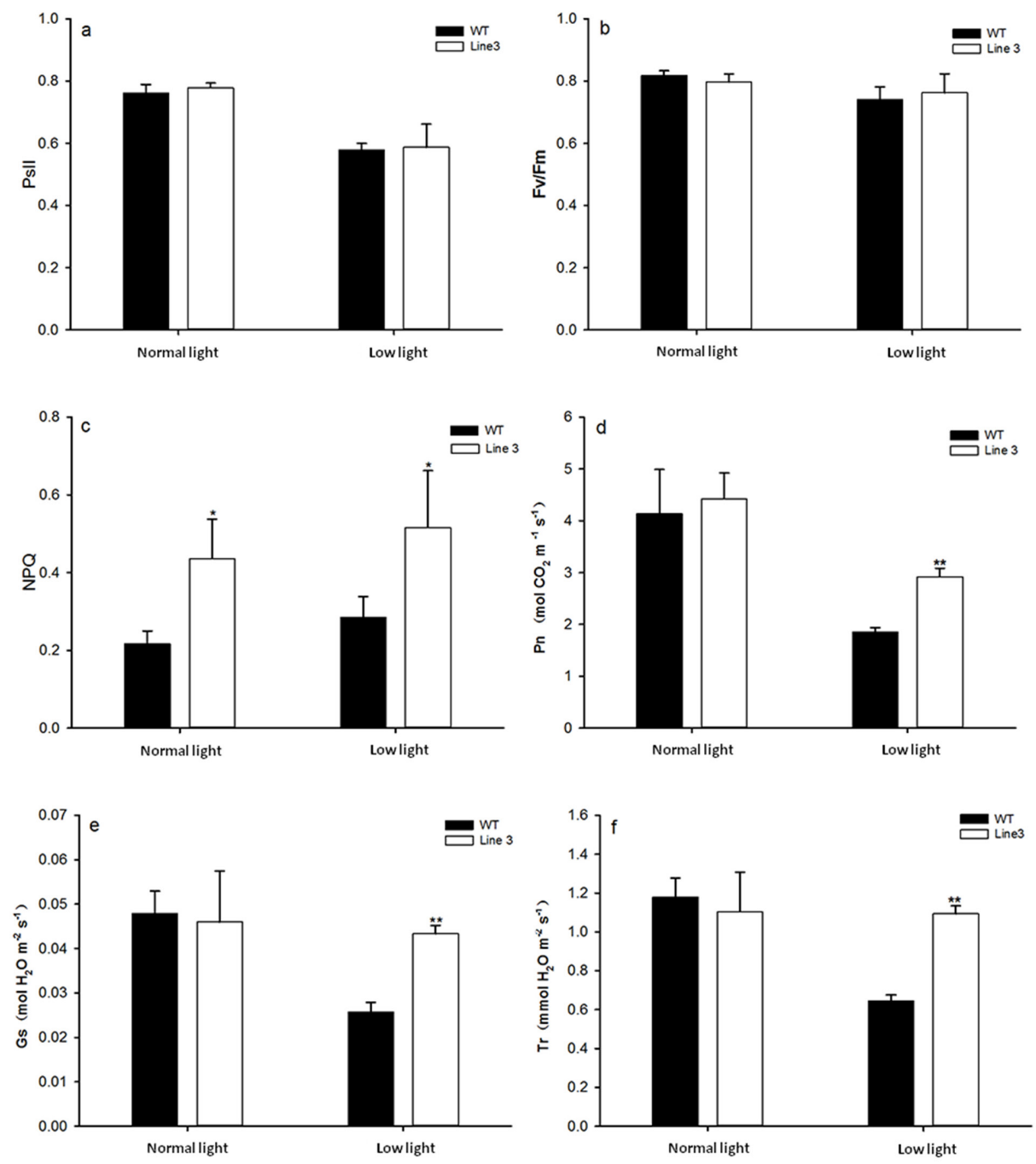

Figure 4. Effect of weak-light stress on the photosynthesis of WT and transgenic plants.

(a) Quantum yield of PSII. (b) Maximal photochemical efficiency of PSII. (c) Non-photochemical quenching. (d) Net photosynthetic rate. (e) Stomatal conductance. (f) Transpiration rate. Bars represent the means \pm S.E. $(n=3)$; asterisk and double asterisk indicate $p \leq 0.05$ and $p \leq 0.01$, respectively. 


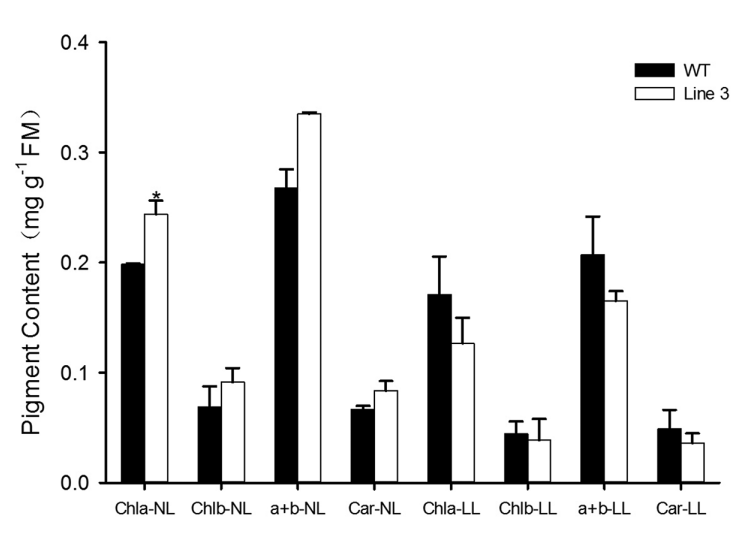

Figure 5. Effect of weak-light stress on pigment content of WT and transgenic plants.

Bars represent the means \pm S.E. $(n=3)$; asterisk indicates $p \leq 0.05$; NL represents normal light, and LL represents low light.

ly, ABA content in MsZEP-overexpression tobacco was higher than in WT (Zhang et al., 2016). The increased ABA content in MsZEP-overexpressors may increase stomatal density under low-light stress, while the phenomenon was not significant under normal growth conditions.

\section{Photosynthetic characteristics}

To investigate the effect of MsZEP gene on photosynthesis levels after weak-light treatment, photosynthetic activity of wild-type and transgenic tobacco was assessed. As shown in Fig. 4, the maximum quantum efficiency of PSII $\left(F_{\mathrm{v}} / F_{\mathrm{m}}\right)$ value and quantum yield of PSII (ФPSII) value of the two plant types decreased after weak-light treatment, indicating a decrease in the rate of light energy conversion (Fig. $4 \mathrm{a}$ and $4 \mathrm{~b}$ ). This contributes to the decline of photosynthetic ability. However, the difference in DPSII and $F_{\mathrm{v}} / F_{\mathrm{m}}$ between WT and $M s Z E P$-overexpression tobacco was not significant, neither under normal nor low light (Fig. 4a and 4b).

Xanthophyll cycle is tightly related to the dissipation of excess light in plants, and NPQ represents the energy which cannot be utilized in photosynthesis and is dissipated harmlessly as heat energy (Veres et al., 2006; Müller et al., 2001; Vasil'ev et al., 1998). In our research, when plants were grown in normal-light condition after the low-light treatment, NPQ increased in both wild and MsZEP-overexpression tobacco, reaching $18.22 \%$ and $30.65 \%$, respectively (Fig. 4c). In addition, the NPQ of $M s Z E P$-overexpression tobacco was always higher than in wild-type under both conditions $(p \leq 0.05)$ (Fig. 4c). Xanthophyll-cycle pigments $(\mathrm{Vx}, \mathrm{Ax}, \mathrm{Zx})$ are involved in the process of NPQ of chlorophyll fluorescence which is the most important mechanism of photoprotection (Demmig\& Adams, 1991). The increase of NPQ value may be due to the expression of MsZEP in transgenic plants. This indicates that overexpressing MsZEP may improve plants' sensitivity to light. Similar results were observed for zeaxanthin epoxidase gene in tomato (Wang et al., 2008).

Under normal-light conditions, leaf net photosynthesis (Pn), stomatal conductance (Gs) and transpiration rate $(\mathrm{Tr})$ displayed no significant difference between MsZEP-overexpression and WT tobacco (Fig. 4d, 4e and 4f). When plants were exposed to low light level, Pn decreased significantly, but in transgenic plants was higher than in W'T $(p \leq 0.01)$ (Fig. 4d), which suggests that overexpressing MsZEP enhances the photosynthetic ability under weak light. The changes of Gs and $\operatorname{Tr}$ were similar to Pn (Fig. 4e and 4f). The higher stomatal density of $M s Z E P$-overexpression tobacco may lead to the higher Gs. In addition, the higher Gs can contribute to the higher Pn and Tr. Therefore, the higher stomatal density may benefit photosynthesis and growth of plants.

\section{Pigment content}

Chlorophyll absorbs light energy during photosynthesis and the content of $\mathrm{Chl} \mathrm{a}$ is three times higher than Chl b. Bell reported that the content of chlorophyll decreased under low-light stress applied for a long time (Bell \& Danneberger, 1999), while Lakshmi and Singh revealed that the content of both $\mathrm{Chl} \mathrm{a}$ and $\mathrm{Chl} \mathrm{b}$ increased and the rate of $\mathrm{Chl} \mathrm{b}$ increase was higher (Praba et al., 2004; Singh et al., 1988). In the present study, the concentration of $\mathrm{Chl} \mathrm{a,} \mathrm{Chl} \mathrm{b}$ and carotenoids in wildtype and MsZEP-overexpression tobacco decreased after low-light stress (Fig. 5). However, the difference between MsZEP-overexpression and WT tobacco was not significant except for chlorophyll a content under normal-light condition. Therefore, MsZEP may enhance the tolerance of tobacco to weak light via other mechanism than by altering chlorophyll and carotenoids levels.

In conclusion, overexpressing MsZEP can improve the ability of tobacco to withstand low-light stress, because MsZEP-overexpression tobacco grew faster than WT. Although NPQ of MsZEP-overexpression tobacco was higher, the photosynthesis rate of $M s Z E P$-overexpression tobacco was also higher than WT tobacco. This may be due to the higher density of stomata in MsZEPoverexpression tobacco.

\section{Acknowledgements of Financial Support}

This work was supported by the Project of National Natural Science Foundation of China (31572456; 31772660) and China Agriculture Research System (CARS-34).

\section{REFERENCES}

Agrawal GK, Yamazaki M, Kobayashi M, Hirochika R, Miyao A, Hirochika H (2001) Screening of the rice viviparous mutants generated by endogenous retrotransposon tos 17 insertion. Tagging of a zeaxanthin epoxidase gene and a novel OsTATCGene. Plant Physiol 125: 1248-1257. https://doi.org/10.1104/pp.125.3.1248

Audran C, Borel C, Frey A, Sotta B, Meyer C, Simonneau T, MarionPoll A (1998) Expression studies of the zeaxanthin epoxidase gene in Nicotiana plumbaginifolia. Plant Physiol 118: 1021-1028. https://doi. org/10.1104/pp.118.3.1021

Barrero JM, Piqueras P, González-Guzmán M, Serrano R, Rodríguez PL, Ponce MR, Micol JL (2005) A mutational analysis of the $A B A 1$ gene of Arabidopsis thaliana high lights the involvement of ABA in vegetative development. J Exp Bot 56: 2071-2083. https://doi. org/10.1093/jxb/eri206

Bell G, Danneberger T (1999) Temporal shade on creeping bentgrass turf. Crop Sci 39: 1142-1146. https://doi.org/10.2135/cropsci1999.0 011183X003900040032x

Bjorkman O, Boardman N, Anderson JM, Thorne S, Goodchild D, Pyliotis N (1972) Effect of light intensity during growth of Atriplex patula on the capacity of photosynthetic reactions, chloroplast components and structure. Carnegie Institution Year Book 71: 115-135

Bugos RC, Hieber AD, Yamamoto HY (1998) Xanthophyll cycle enzymes are members of the lipocalin family, the first identified from plants. J Biol Chem 273: 15321-15324. https://doi.org/10.1074/ jbc. 273.25 .15321

Della PD, Pogson BJ (2006) Vitamin synthesis in plants: tocopherols and carotenoids. Annu Rev Plant Biol 57: 711-738. https://doi. org/10.1146/annurev.arplant.56.032604.144301

Demmig-Adams B, Adams WW (1996) The role of xanthophyll cycle carotenoids in the protection of photosynthesis. Trends Plant Sci 1: 21-26. http://dx.doi.org/10.1016/S1360-1385(96)80019-7 
Elhaddad NS, Hunt L, Sloan J, Gray JE (2014) Light-induced stomatal opening is affected by the guard cell protein kinase APK1b. PloS One 9: e97161. https://doi.org/10.1371/journal.pone.0097161

Farquhar GD, von Caemmerer S, Berry JA (2001) Models of photosynthesis. Plant Physiol 125: 42-45. https://doi.org/10.1104/pp.125.1.42

Franks PJ, Farquhar GD (2001) The effect of exogenous abscisic acid on stomatal development, stomatal mechanics, and leaf gas exchange in Tradescantia virginiana. Plant Physiol 125: 935-942. https:// doi.org/10.1104/pp.125.2.935

Frommolt R, Goss R, Wilhelm C (2001) The de-epoxidase and epoxidase reactions of Mantoniella squamata (Prasinophyceae) exhibit different substrate-specific reaction kinetics compared to spinach. Planta 213: 446-456. https://doi.org/10.1007/s004250100589

Hieber AD, Bugos RC, Yamamoto HY (2000) Plant lipocalins: violaxanthin de-epoxidase and zeaxanthin epoxidase. BBA-Protein Struct $M$ 1482: 84-91. https://doi.org/10.1016/S0167-4838(00)00141-2

Kang H, Zhu Y (2003) Observation of large Kerr nonlinearity at low light intensities. Phys Rev Lett 91: 093601. https://doi.org/10.1103/ PhysRevLett.91.093601

Latowski D, Grzyb J, Strzałka K (2004) The xanthophyll cycle-molecular mechanism and physiological significance. Acta Physiol Plant 26: 197. https://doi.org/10.1007/s11738-004-0009-8

Lee SH, Tewari RK, Hahn EJ, Paek KY (2007) Photon flux density and light quality induce changes in growth, stomatal development, photosynthesis and transpiration of Withania somnifera (L.) Dunal. plantlets. Plant Cell Tiss Org 90: 141-151. https://doi.org/10.1016/j. cej.2004.01.016

Lichtenthaler H, Buschmann C, Döll M, Fietz HJ, Bach T, Kozel U, Meier D, Rahmsdorf U (1981) Photosynthetic activity, chloroplast ultrastructure, and leaf characteristics of high-light and low-light plants and of sun and shade leaves. Photosynth Res 2: 115-141. https://doi.org/10.1007/BF00028752

Müller P, Li XP, Niyogi KK (2001) Non-photochemical quenching. A response to excess light energy. Plant Physiol 125: 1558-1566. https://doi.org/10.1104/pp.125.4.1558

Marin E, Nussaume L, Quesada A, Gonneau M, Sotta B, Hugueney P, Frey A, Marion PA (1996) Molecular identification of zeaxanthin epoxidase of Nicotiana plumbaginifolia, a gene involved in abscisic acid biosynthesis and corresponding to the $A B A$ locus of Arabidopsis thaliana. EMBO J 15: 2331

Murashige T, Skoog F (1962) A revised medium for rapid growth and bio assays with tobacco tissue cultures. Physiol Plantarum 15: 473-497

Murchie EH, Horton P (1997) Acclimation of photosynthesis to irradiance and spectral quality in British plant species: chlorophyll content, photosynthetic capacity and habitat preference. Plant Cell Environ 20: 438-448. https://doi.org/10.1046/j.1365-3040.1997.d01-95.x

Nambara E, Marion-Poll A (2005) Abscisic acid biosynthesis and catabolism. Annu Rev Plant Biol 56: 165-185. https://doi.org/10.1146/ annurev.arplant.56.032604.144046

Pan J, Guo B (2016) Effects of light intensity on the growth, photosynthetic characteristics, and flavonoid content of Epimedium pseudowushanense BL Guo. Molecules 21: 1475. https://doi.org/10.3390/ molecules21111475

Park HY, Seok HY, Park BK, Kim SH, Goh CH, Lee BH, Lee CH, Moon YH (2008) Overexpression of Arabidopsis ZEP enhances tolerance to osmotic stress. Biochemical and biophysical research communications 375: 80-85. https://doi.org/10.1016/j.bbrc.2008.07.128

Pastenes C, Pimentel P, Lillo J (2005) Leaf movements and photoinhibition in relation to water stress in field-grown beans. J Exp Bot 56: 425-433. https://doi.org/10.1093/jxb/eri061
Peyami B, Mehmet E, Musa T, Ismet B (2008) Molecular and physiological changes in maize (Zea mays) induced by exogenous NAA, $\mathrm{ABA}$ and MeJa during cold stress. ANN BOT FENN 45: 173-185. https://doi.org/10.5735/085.045.0302

Praba ML, Vanangamudi M, Thandapani V (2004) Effects of low light on yield and physiological attributes of rice. Int Rice Res Notes 29: $1-1$

Romanowska E, Powikrowska M, Zienkiewicz M, Drozak A, Pokorska B (2008) High light induced accumulation of two isoforms of the CF1 alpha-subunit in mesophyll and bundle sheath chloroplasts of C4 plants. Acta Biochim Pol 55: 175

Sæbø A, Krekling T, Appelgren M (1995) Light quality affects photosynthesis and leaf anatomy of birch plantlets in vitro. Plant Cell Tiss Org 41: 177-185. https://doi.org/10.1007/bf00051588

Schwarz N, Armbruster U, Iven T, Brückle L, Melzer M, Feussner I, Jahns P (2014) Tissue-specific accumulation and regulation of zeaxanthin epoxidase in Arabidopsis reflect the multiple functions of the enzyme in plastids. Plant Cell Physiol: pcu167.https://doi. org/10.1093/pcp/pcu167

Singh V, Dey S, Murthy K (1988) Effect of low light stress on growth and yield of rice. Indian I Plant Physiol 31: 84-91

Vasil'ev S, Wiebe S, Bruce D (1998) Non-photochemical quenching of chlorophyll fluorescence in photosynthesis. 5-hydroxy-1, 4-naphthoquinone in spinach thylakoids as a model for antenna based quenching mechanisms. BBA-Bioenergetics 1363: 147-156. https:// doi.org/10.1016/S0005-2728(97)00096-0

Veres S, Tóth V, Láposi R, Oláh V, Lakatos G, Mészáros I (2006) Carotenoid composition and photochemical activity of four sandy grassland species. Photosynthetica 44: 255-261. https://doi. org/10.1007/s11099-006-0016-7

Wang N, Fang W, Han H, Sui N, Li B, Meng QW (2008) Overexpression of zeaxanthin epoxidase gene enhances the sensitivity of tomato PSII photoinhibition to high light and chilling stress. Physiol Plantarum 132: 384-396. https://doi.org/10.1111/j.13993054.2007.01016.x

Wilson JW, Hand D, Hannah M (1992) Light interception and photosynthetic efficiency in some glasshouse crops. J Exp Bot 43: 363373. https://doi.org/10.1093/jxb/43.3.363

Xiong L, Lee H, Ishitani M, Zhu JK (2002) Regulation of osmotic stress-responsive gene expression by the LOS $6 / A B A 1$ locus in Arabidopsis. J Biol Chem 277: 8588-8596. https://doi.org/10.1074/ jbc.M109275200

Yamamoto HY, Higashi R (1978) Violaxanthin de-epoxidase: lipid composition and substrate specificity. Arch Biochem Biophys 190: 514 522. https://doi.org/10.1016/0003-9861(78)90305-3

Yang Y, Sun X, Yang S, Li X, Yang Y (2014) Molecular cloning and characterization of a novel SK3-type dehydrin gene from Stipa purpurea. Biochem Bioph Res Co 448: 145-150. https://doi.org/10.1016/j. bbrc.2014.04.075

Zhang Z, Wang Y, Chang L, Zhang T, An J, Liu Y, Cao Y, Zhao $\mathrm{X}$, Sha X, Hu T (2016) MsZEP, a novel zeaxanthin epoxidase gene from alfalfa (Medicago sativa), confers drought and salt tolerance in transgenic tobacco. Plant Cell Rep 35: 439-453. https://doi. org/10.1007/s00299-015-1895-5

Zoratti L, Karppinen K, Luengo Escobar A, Häggman H, Jaakola L (2014) Light-controlled flavonoid biosynthesis in fruits. Front Plant Sci 5: 534. https://doi.org/10.3389/fpls.2014.00534 